\title{
An Expansive Model of Business Process and IT/EIS Fusion-Integration Based on Enterprise Engineering
}

\author{
Hongjun Liu, Xuejie Qin and Yong Yang \\ College of Information Management, Chengdu University of Technology, Chengdu 610059, \\ P.R.China liuhj@cdut.cdu.cn qinxuejie001@163.com yangyong810203@163.com
}

\begin{abstract}
This article analyzes the complexity and dynamic of each kind of commerce network architecture from the system engineering. The thesis uses the complex self-adaptive system to describe the process of enterprise commerce network evolutionary. Bases on the drawing mechanism from enterprise commerce network transaction flow to the IT/EIS (information technology/enterprise information system) function demand, proposes a fusion expansion model which is from the commercial network concept integration, to logic integration and physics integration. The model is based on agent and the component technology. It tracks the new progress of information management technology and expenses the communication and coordination between the network insider and outsider, as well as the study function which must be calculated according to requirements. As a result, the model changes traditional IT/EIS platform that is only for improving working efficiency and guiding decision tools into the modern enterprise's blood supply system and nervous system. The model takes advantage of enhancing the validity of enterprise information construction.
\end{abstract}

Keywords: Enterprise engineering, Business process, Information technology, Enterprise information systems, Agent and the component technology, Commerce network, Integration

\section{INTRODUCTION}

Now the information technology is developing rapidly and the requirements of business to information systems are much more. The information system which the enterprise needs are no longer only the tools to satisfy the working efficiency enhancement and assistance the enterprise decision-making, but should become the blood supply system and the nervous system for the whole enterprise system. The enterprise faces with the complex commercial network. The first question is how to fuse own business process and the correlation domain knowledge into information system. We can not view the enterprise information construction on isolated and static. It is easy to access the misunderstanding of technology. It's difficult to support the changing needs for enterprise commerce network effectively.

Michael Hammer proposed the "Reengineering" thought in 1990. Engineering was first introduced to enterprise management. As a result, the concept of Enterprise

Please use the following format when citing this chapter:

Liu, H., Gin, X., Yang, Y., 2007, in IFIP International Federation for laformation Processing, Volume 255, Research and Practical Issues of Enterprise Information Systems II Volume 2, eds. L. Xu, Tjoa A., Chaudhry S. (Boston: Springer), pp. 869-878. 
Engineering begins to develop. James Martin induced EE (Enterprise Engineering) for five transformation methods and two foundation changing processes in 1995 . One foundation changing process is the information technology development and the other is the development of organization \& the cultural [1]. The information technology development may regard as one kind of producer goods. It supports the enterprise transform process.

This article proposes a fusion expansion model between business process and IT/EIS. It's inspired by Toyota pattern which is led the material after working procedure- "the drawing type production" [2].And the model is based on whole framework of Enterprise Engineering. That is making the commercial network value match with the information flow, then planning, designing, implementing and maintaining the IT/EIS platform to draw the enterprise's information construction effectively.

\section{ENTERPRISE ENGINEERING DRAWING MECHANISMS AND SYSTEM INTEGRATION TECHNOLOGY}

\subsection{Enterprise Engineering Drawing Mechanism}

Enterprise engineering may think as the development of BPR (Business Process Reengineering) and the theory of organization study. Its producing background is the enterprise transformation and the correlation engineering factor's maturity. It is the discipline aggregate which used in constructing or transforming the enterprise and its process and system. It unifies the most powerful transformation method and makes them success. The goal is achieves the biggest effect in all level study which the technology and the human unify [1]. The modern information technology and the high quality talents are the two foundations implementation of business process reengineering. The theory of "study organization" proposed it can create an advantageous organization environment by way of the independent study and the coordination study. You must complete the reform between cognition and behavior.It's the foundation for organization innovation.

Proposed custom-made the enterprise commerce network IT/EIS platform under enterprise engineering framework is in order to emphasize the business demand decision enterprise information technology adoption. It can eliminate the "two skins" phenomenon which comes from enterprise management transformation and the enterprise information construction. Then makes integration between enterprise information and information engineering. Let the information flow which sources from enterprise business flow finally serve the enterprise business flow. 


\subsection{Development of System Integration Technology}

Now the economical characteristic is e, "immediate", globalization and digitization. Stephen Haag and so on [3] once pointed out that: Today the known multitudinous new technologies are used to enhance the efficiency, the communication and the coordination, and the intellectualized level in the organization. They are all revolving 6 tendencies. The 6 tendencies are: Information filtration demand, intelligent computation development, physiological interactive way transformation, the portable and motion technology, digitized front domain, electronic commerce's rises. They influence organizations development profoundly.

Claus. E. Heinrich, the executive director of SAP AG, has defined a "compatible commercial network" concept [4]. He divides the compatible commercial network establishment into fours processes: The transparence, the alliance, the cooperation and adaptation. Along with the advancement evolution, the information technology and the component which needs to use also increases unceasingly. Heinrich describes an engineering method for us. That is how to make a new competitive powerful enterprise under the new economic environment.

In recent years, IBM initiates "according to need to change" sparely no effort. They forecast, diagnosis, elimination breakdown self-repair. The balance working load, maximum limit displays the resources superiority the self-optimization. But in order to realize "according to need to change", the development personnel faces several prominent questions. They are: (1Fuses the advanced management thought and the correlation domain knowledge into the information system; D Enhances the extendibility and the flexibility of the system, meets need which changes unceasingly; (3) Realizes code entrusts with heavy responsibility, integrates or transplants the massive value extremely system resources to the new system.

The formerly system integration begins with physical connection to the software and the data integration. But this article proposes the system fusion expansion pattern is not limited in the data fusion. It emphasizes the business demand decision enterprise to information technology adoption. It realizes the enterprise engineering and the information engineering integration through the enterprise auto-adapted information system and the commercial network fusion. In the aspect of realization technology, it takes the network, the data warehouse and object-oriented three mainstream technologies as the foundation. The development pattern is based on Agent and the component. Then the advanced management thought and the correlation domain knowledge are fusion together. The goal which is constructing the information system that can satisfy with the different enterprise demand and the enterprise demand change is realized.

\section{FUSION EXPANSION MODEL}

The establishment process of fusion expands IT/EIS platform which satisfies the complex commercial network's need are as follows. 


\subsection{Structure of Enterprise Commerce Network}

The diffusion structure, the chaos, the sudden change, the coordination, fractal and the ultra circulation are branches theories of complex system. The common characteristic of them is discussion the nonlinear response nature or the humanities phenomenon. But in the man-made complex system- "enterprise commerce network", the information is the more basic element which restricts its development from an organization action (the "slow factor" decides the moving towards of system function and structure). It is also the heredity characteristic for the enterprise's life body (evolution and branch) [5].

The management pattern expedites childbirth by Internet-"virtual enterprise" is a typical man-made complex system. Bonn et al. once proposed four kinds of virtual enterprise's classical pictures, namely asteroid alliance model, equal alliance model, value alliance model and market alliance model. In fact, from the angle of complex self-adaptive system analysis, we may take Bonn et al.'s classification of virtual enterprises as the classification of enterprise commerce network by virtual degree. Entrusts with them the stage evolution attribute from "the asteroid alliance" which emphasized the information network joins, "the equal alliance" (to be called enterprise conformity)which face the product management process integration, "the value alliance" and "the market alliance" (is called enterprise dynamic alliance) in the time.

Under the new economic environment, no matter which kinds of enterprise commerce network are usually all need to establish a foundation platform by four nets composed together, such as the knowledge/skill network, the information network, the physical distribution network and the dynamic contract network. The knowledge/skill network which manifests the enterprise core ability as well as the physical distribution network is the movement premise of this entire foundation platform. The information network is the technical support of entire movement platform. The dynamic contract network which connection multi-dimensional main body is the successful safeguard for commercial network operates. As the system is complexity, the enterprise needs to place the information platform construction into the whole plan of enterprise engineering to examine carefully.

\subsection{The Concept Integrates}

The system's concept integration must construct from the total goal of enterprise system. In the space, it takes the knowledge/skill network which can manifest the enterprise core ability as the core to distinguish the function essential factor in the enterprise commerce network (including business flow and information flow). Then design or optimize the foundation platform which gathers with four networks in the enterprise commerce network. It causes the knowledge/skill, the information, the physical distribution and the dynamic contract (system) each other blends. In the same time, it strengthens "the slow factor" and integrates all function modules effectively. In the time, it passes through each stage of IT/EIS construction to seek a solution. The solution is not only satisfying this stage's basic need but also carrying on "the promotion" in the enterprise system following evolutionary process. 
One four structures "the house" shape model available describe the operation construction of enterprise commerce network (Figure 1.). Safeguard level (first floor): Including the network infrastructure. It provides the basic safeguard for the system integration; Support level (second floor): It includes besides each kind of application database which the enterprise original have, but also includes the enterprise knowledge library. The enterprise knowledge library is supported by data warehouse technical. It can satisfy enterprise knowledge to precipitate, knowledge sharing, knowledge increment needs; Operation level (third floor): It's the set of enterprise systems. It is different with the traditional application system. Here each operational channel is based on the knowledge/skill. It is the carrier of enterprise core ability. They enable the enterprise knowledge to obtain precipitate effectively and management during processing the daily business. And they can facilitates the cooperation and optimization the business flow; Strategic level (roof):This level requests the enterprise stands in the strategy highly to inspect the entire commercial network, and realizes accurate appraisal to the enterprise external environment and the core ability its own has. Then the enterprise formulates the strategic plan. On the organization construction, it provides the guarantee for the business management and the operation successfully.

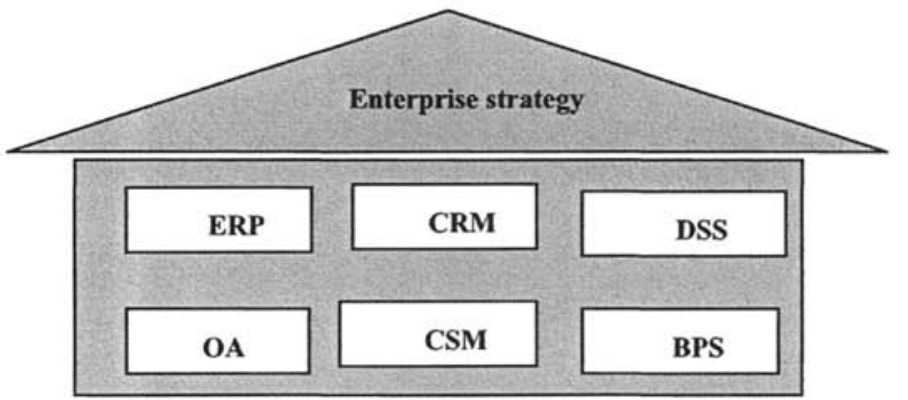

Enterprise knowledge library

Infrastructure (client, server, network)

Strategic level<smiles>C1=CCCCC1</smiles>

Operation level

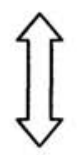

Support level

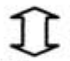

Safeguard level

Figure 1. Based on Knowledge/Skill Management Information System Operation Construction

Realizes the above model's advancement method is the enterprise engineering method. It is from the whole to the partial, carrying on the advancement from the top to downward. Its mechanism is draws the operation level, the support level by the business demand, until first floor. 


\subsection{The Logic Integrates}

After established the system output goal we make the logic integrates according the IDEF method. The factor which needs to consider besides input and switching process, but also should include the limiting factor of environment to the system (for instance, opportunity, core ability, partner, enterprise restructures, agility, organization movement pattern and so on). Take the opportunity target as an example, the factors are: The market demand, the thunderbolt, the policy adjustment, the culture transform, the enterprise strategy, the technological development, the customer value, the expense tendency and the consumption pattern and so on. The enterprise commerce network eliminates "the restraint" through using "virtual" and "the expansion" and so on operation mechanisms. Then achieves the system anticipated output goal.

Table 1. Commercial Network IT/EIS Analysis Framework

\begin{tabular}{|l|l|l|l|l|}
\hline $\begin{array}{l}\text { Evolution } \\
\text { stage } \\
\text { commercial } \\
\text { network }\end{array}$ & $\begin{array}{l}\text { Enterprise } \\
\text { commerce } \\
\text { network } \\
\text { architecture }\end{array}$ & $\begin{array}{l}\text { Information } \\
\text { system } \\
\text { pattern }\end{array}$ & $\begin{array}{l}\text { Operational } \\
\text { mechanism and } \\
\text { function demand }\end{array}$ & $\begin{array}{l}\text { Related technology (and } \\
\text { typical demonstration) }\end{array}$ \\
\hline $\begin{array}{l}\text { Initial period } \\
\text { stage }\end{array}$ & $\begin{array}{l}\text { Star type } \\
\text { structure }\end{array}$ & $\begin{array}{l}\text { Efficiency } \\
\text { guidance }\end{array}$ & $\begin{array}{l}\text { Value chain } \\
\text { conformity and } \\
\text { special } \\
\text { permission } \\
\text { management } \\
\text { pattern }\end{array}$ & $\begin{array}{l}\text { Hegemonic enterprise: } \\
\text { intranet and extranet } \\
\text { structure; Systems and so } \\
\text { on ERP, CRM, OA, } \\
\text { EC.(Wal-Mart and so on) }\end{array}$ \\
$\begin{array}{ll}\text { Eartner enterprise (or } \\
\text { subordinate entity): Builds } \\
\text { own according to own } \\
\text { characteristic special- } \\
\text { purpose information } \\
\text { system.(Wal-Mart's } \\
\text { suppliers) }\end{array}$ \\
\hline Growth stage & $\begin{array}{l}\text { Ring } \\
\text { structure }\end{array}$ & $\begin{array}{l}\text { Robust } \\
\text { guidance }\end{array}$ & $\begin{array}{l}\text { "The equality" } \\
\text { partner enterprise } \\
\text { communicates } \\
\text { and coordinates }\end{array}$ & $\begin{array}{l}\text { Alone constructs a set } \\
\text { correspondingly to use in } \\
\text { common the system; } \\
\text { Perhaps uses respective } \\
\text { system docking the way to } \\
\text { carry on the work.(Project } \\
\text { unit exploitation) }\end{array}$ \\
\hline Mature stage & $\begin{array}{l}\text { Laminated } \\
\text { structure } \\
\text { (core } \\
\text { periphery) }\end{array}$ & $\begin{array}{l}\text { Synthesis } \\
\text { guidance }\end{array}$ & $\begin{array}{l}\text { The federation } \\
\text { pattern, the } \\
\text { industrial } \\
\text { production } \\
\text { manages }\end{array}$ & $\begin{array}{l}\text { Standardized technology, } \\
\text { safe support; Call center } \\
\text { pattern, electron } \\
\text { transmission modes and so } \\
\text { on EDI.(Capital electron } \\
\text { commercial city) }\end{array}$ \\
\hline
\end{tabular}

In the foundation of predecessor research results, we establish the three kinds of information system pattern. These three patterns correspond separately with the enterprise commerce network's development stages, from initial period stage, the growth stage to the mature stage (see Table 1.). 
In fact, between these three kinds of information system patterns has one kind of evolution expansion relation. Its complex degree must be much far higher than here describes. Introduction $\mathrm{EE}$ is the important way to construct the true effective IT/EIS platform. It eliminates the demand comes apart and fuses the information system plan design during the enterprise commerce network whole plan's design.

\subsection{The Physics Integrates}

The networking, data warehouse technology and object-oriented technology are three mainstream technologies to the software engineering now. In the foundation of these technical, we choose the development pattern which based on Agent and the component ([7]; [8]; and [9]).The IT/EIS platform can meet the different enterprise's needs and the changing demands. It is the ideal technical to enhance the extendibility and the flexibility of enterprise commerce network system. It realizes the advanced management thought and the correlation domain knowledge's combination.

The development pattern is shown in Figure 2. It based on Agent and the component. The concept level corresponds with the strategic level and the operation level which described in the preamble business model. The logical level corresponds with the support level and the physical level corresponds with the safeguard level. According to the object-oriented thought, here each all may realize the fusion of the process assembly and the knowledge assembly. In the concept level, the demand analysis and the domain analysis make the correlation domain and the profession knowledge abstraction, the generalization and the parameterization, and establish the corresponding domain model. The domain model finally evolves for logical level's agent, and completes mapping from the concept level to the logical level. In the logical level, it completes the knowledge structure's assembly through assembly design by the Agent's cascade nesting. We use the component and combination component to assembly the atom Agent. It can complete the mapping from the logical level to the physical level. In the physical level, we realize application information system process assembly through core component development and cascade nesting assembly. Thus, it integrates the knowledge assembly to the process assembly, and completes the knowledge through the process assembly the assembly, has integrated the knowledge/skill in the information system.

As mentioned above, system realized according to this pattern is actuated by the knowledge/technology. Therefore, the system auto-adapted performances can (concept level) realize along with the strategic level to the commercial network change response. Based on the agent component's information systems are no longer the pure data processing and the analysis tool, but the blood supply system and the nervous system. They can make the fast response to the market shift by the knowledge/technology actuation. 


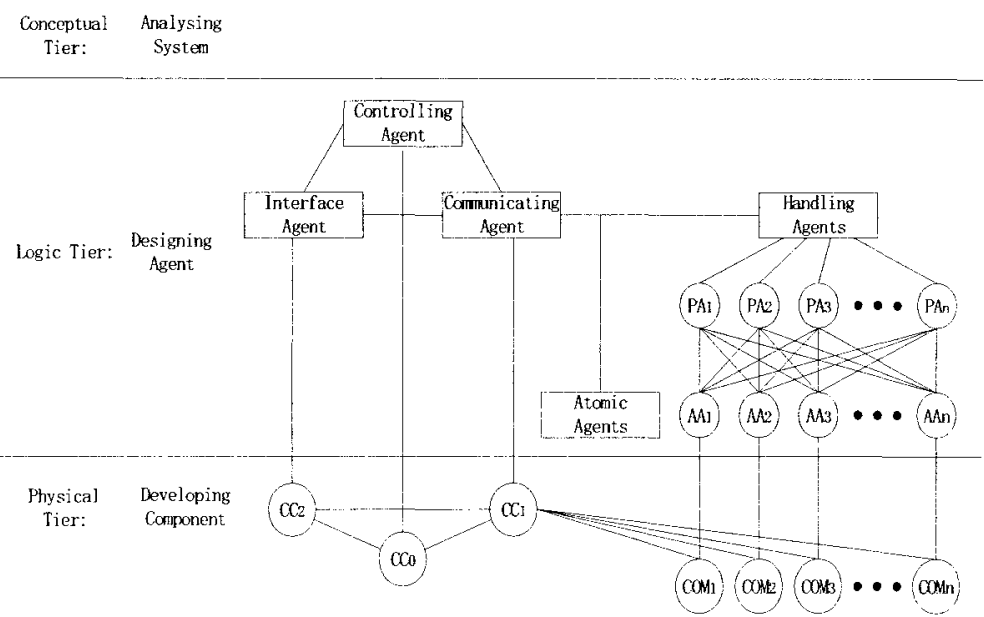

PAi represents handling Agent,

AAi represents atomic Agnet,

CoMi represents component and combined component composing atomic Agnet,

$\mathrm{CCO} 、 \mathrm{CC} 1$ and $\mathrm{CC} 2$ represents combined component composing

respectively controlling Agent, communicating Agent and interface

Agnet

Figure 2. Development Patterns of Information System Based on Agent and Component Object

\section{THE DESCRIBES OF FUSION PROSPECT}

The relation of enterprise engineering construction and the informational engineering implementation belongs to the overall situation and partial, the whole and the part. As mentioned above, our goal is constructs the enterprise into an organization system which has the goal and the environment highly compatible. The EE cannot leave the information technology from designation to implementation. It is not only the precise method and tool to describe the enterprise blueprint by logic; simultaneously it's also the basic material, method and method for "foundation enterprise's project". Thus, the IT/EIS plan design fused during enterprise plan design.

Enterprise Engineering driven mechanism in the enterprise information are: 1) Enterprise information success in the transformation. Implement EE is an effective way of Enterprise complete system and mechanism innovation. 2) Guided by the goal of EE to pull enterprise information, conduct enterprise design from the bottleneck, and undertake the necessary restructuring and business process optimization. 3) It 
needs enhance the ability of decision-maker to command of information. Chinese enterprises should attach importance to the training CIO and exampling enterprise information leadership to improve the perform power of enterprise information.4) Eliminate the phenomenon of business and technology among industries. Build information platform based on the whole design of EE. It can avoid the warp may arise from business and technology combination [2].

The combinations of business process and IT/EIS can be achieved by way of enterprise engineering pull mechanism, as follows:

1) integration (integrated): See enterprise system as a complete targeted, in the colligate sustain of information technology, system integration technology, modern management techniques and other integrated technical, make enterprise engineering and modern information engineering as support, so as to continuously achieve the target area, functional domain and time domain fully coupling. Lean enterprise system architecture and functional integration of the sum.

2) Personality: The "made to measure is" information model which based on enterprise process can create their unique competitive advantages.

3) Variability: Include changes of enterprise scale, rules, partners, organizational structure and so on change rapidly at any time. EIS must be built for the change of management.

4) Opening: Open platform, open agreement, embodied the coexistence strategy between organization and outside.

5) Use easily: Relation with open, user-friendly nature is to bring about a "free training."

To achieve these objectives, the enterprise design engineers need to work together with the IT engineers. As a result, there is the traditional "policy managers" of some people-oriented task changes to the technical personnel, a sophisticated task. They rely on the enterprise operation platform (the core is information platform) to generate personalized business pattern and the business pattern changes and improvement program. From the perspective of the social division of labor, enterprise design engineers played a role in the promotion of advanced thinking; IT engineers (vendors of information technology or software) serve as developers or builders for enterprise information system and other IT platform.

\section{CONCLUSIONS}

In summary, this article proposed an information system fusion integration pattern under the enterprise engineering framework which based on Agent and the component auto-adapted. It is different from the former system integration realization process which begins in physical connection to the software and the data integration again. This article proposed the fusion expansion model. It is an enterprise business flow actuation model. It bases on the engineering method, from the whole to partial, and carries on the advancement from the top to downward. It is not only realizing the fusion, but also increases the system's expansion function in the same time. 


\section{REFERENCES}

1. J. Martin, The Great Transition-Using the Seven Disciplines of Enterprise Engineering to Align People Technology and Strategy (Tsinghua Press: Beijing, PK, 1999).

2. H. Liu, Why is the Chinese Enterprise Informationization Difficult to Have the Substantive Progress, Chinese information. Volume 90, Number 2, pp.37-40, (2007).

3. S. Haag, M. Cummings, D.J. McCubbrey, and J. Yan translates, Management Information System for the Information Age (China Machine Press: Beijing, PK, 2004).

4. C.E. Heinrich, B. Betts, T. Wang, and X. Xie, Translate the Survival of the Fittest - Supplies the Chain to Transform into the Compatible Commercial Network (The Eastern Press: Beijing, PK, 2005).

5. Z. Mao, The Complex System Viewpoint Organization Transforms the Theory, in The Third Session of China Management Science and the Project Academic Forum. Volume 206, 2005 China Management Science and Engineering Development, eds. Q. Ma (Publishing house of electronics industry: Beijing, PK, 2005), pp.1-5.

6. F.M.T. Brazier, C.M. Junker, and J. Truer. Principles of component-based design of intelligent agents, Data \& Knowledge Engineering. Volume 41, Number 1, pp.1-27, (2002).

7. P. Gruyere, V.T. Hillarie, A. Koukama, and K. Cetnarowicz, A formal framework for multi-agent systems analysis and design, Expert Systems with Applications. Volume 23, Number 4, pp.349-355, (2002).

8. H. Ji, Z. Yang, and H. Huang, The New Development of Software Engineering Approach: Agent-Oriented Software Engineering, Application Research of Computers. Volume 5, Number 20, pp.4-7, (2003).

9. S. Shi, X. Wu, and Q. Liu, the Architecture and Business Component Models for Component Information Systems, Computer Engineering \& Science. Volume 5, Number 27, pp.91-93, (2005). 